\title{
Concentração de anticoagulante, tempo e temperatura de armazenagem sobre os parâmetros hematológicos no hemograma automatizado
}

\author{
Anticoagulant concentration, time and storage temperature on hematological parameters in automated \\ blood count
}

\author{
Aécio Carlos de Oliveira ${ }^{\mathrm{I} *}$ José Dantas Ribeiro Filho $^{\mathrm{I}}$ José Domingos Guimarães $^{\mathrm{I}}$ \\ André Ricardo e Silva ${ }^{I}$ Waleska de Melo Ferreira Dantas ${ }^{I}$ Laila de Paula Bonfá ${ }^{I}$ \\ Sheila Kreutzfeld de Farias ${ }^{I}$
}

\section{RESUMO}

O estudo teve como objetivo identificar os efeitos do tempo de estocagem, da temperatura de armazenamento $e$ da quantidade de anticoagulante sobre parâmetros hematológicos de cães. Foram utilizadas amostras do sangue de dez cães de raças variadas, clinicamente hígidos. As alíquotas foram colhidas com 1,8mg; 3,6mg; 7,2mg e 14,4mg de ácido etilenodiaminotetracético (EDTA) por $m L$ de sangue, distribuidas em dois grupos: de $2^{\circ} \mathrm{C}$ a $8{ }^{\circ} \mathrm{C}$ e temperatura ambiente. Após a coleta, foram avaliadas em quatro tempos: $0,12,24$ e 48 horas. Usando um contador automático de células, foram avaliados leucócitos, eritrócitos, hemoglobina, hematócrito, volume corpuscular médio (VCM), indice de anisocitose eritrocitária (RDW), plaquetas e plaquetócrito (PCT). O valor do VCM diminuiu nas maiores concentrações de EDTA $\left(7,2 m g m L^{-1}\right.$ e $\left.14,4 m g ~ m L^{-1}\right)$, com decréscimo de 2,36\% na maior concentração. A temperatura e o tempo de armazenagem também ocasionaram alteração nesse parâmetro, ou seja, houve decréscimo no tempo 12 horas à temperatura de 2 a $8^{\circ} \mathrm{C}$ e aumento nos tempos 24 e 48 horas à temperatura ambiente $(P<0,05)$. A temperatura de conservação influenciou discretamente a contagem de leucócitos e eritrócitos, que apresentaram valores menores na temperatura ambiente. Hemoglobina, hematócrito, plaquetas e PCT não apresentaram alteração significativa. As alterações observadas não comprometeram os resultados obtidos no contador automático, mostrando que as amostras sanguineas, conservadas por 48 horas, mantiveram-se em boas condições para análise. principalmente quando armazenadas à temperatura de 2 a $8^{\circ} \mathrm{C}$.

Palavras-chave: cão, hemograma, EDTA, tempo, temperatura.

\section{ABSTRACT}

The study aimed to identify the effects of time, temperature of storage and excess of anticoagulant on hematological parameters of dogs. Blood samples of ten clinically healthy dogs, of different breeds were utilized. Aliquots were stored with $1.8 \mathrm{mg}, 3.6 \mathrm{mg}, 7.2 \mathrm{mg}$ and $14.4 \mathrm{mg}$ of ethylenediaminetetraacetic acid (EDTA) per $m L$ of blood, divided into two groups: $2^{\circ} \mathrm{C}$ to $8^{\circ} \mathrm{C}$ and room temperature. Right after collection, they were evaluated in four times: Oh, $12 \mathrm{~h}, 24 \mathrm{~h}$ and $48 \mathrm{~h}$. White blood cells, red blood cells, hemoglobin, packed cell volume (PCV), mean corpuscular volume $(M C V)$, red cell distribution width $(R D W)$, platelet and thrombocrit (PCT) were evaluated in the automatic cell counter. In the automatic cell counter analysis, the MCV increased significantly with higher concentrations of EDTA $\left(7.2 \mathrm{mg} \mathrm{mL}^{-1}\right.$

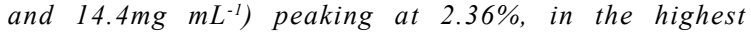
concentration. Temperature and time also influenced the MCV, which showed a decrease in time 12 under temperature of $2^{\circ} \mathrm{C}$ to $8^{\circ} \mathrm{C}$ and an increase in time 24 and 48 at room temperature. Storage temperature influenced leukocytes and erythrocytes counts, which showed lower values at room temperature. Hemoglobin, PCV, platelet and PCT did not change significantly. The changes observed did not compromise the results obtained by automatic cell counter, showing that blood samples stored for two days remained in good condition for processing, especially when stored under refrigeration.

Key words: dog, hemogram, EDTA, time, temperature.

\section{INTRODUÇÃO}

São vários os fatores que contribuem para a má qualidade das amostras hematológicas, dentre eles a pouca quantidade de sangue nos tubos de coleta, levando à distorção da relação sangue/anticoagulante. Como existe uma relação ideal sangue anticoagulante, e os tubos são padronizados com uma quantidade fixa

'Departamento de Veterinária, Universidade Federal de Viçosa (UFV), Avenida P.H. Holfs s/n , 36570-000, Viçosa, MG, Brasil.

E-mail: aecio@ufv.br. *Autor para correspondência. 
de EDTA, percebe-se que, muitas vezes, hemogramas são realizados com amostras obtidas de maneira inadequada, ou seja, com excesso de anticoagulante. Também se observam, com frequência, amostras "velhas" coletadas em finais de semana, em outras localidades ou a campo, durante aulas práticas, realizadas em locais e horários que não permitem o envio e o processamento delas no mesmo dia. Estas alíquotas muitas vezes são conservadas sob temperatura ambiente, por grandes períodos de tempo, o que pode comprometer a qualidade do resultado dos hemogramas.

De uso de rotina como anticoagulante de amostras sanguíneas, o ácido etilenodiaminotetracético (EDTA) em excesso pode ocasionar diminuição do hematócrito e do volume corpuscular médio (VCM), além de aumentar a concentração de hemoglobina corpuscular média (CHCM) sem interferir no resultado da concentração de hemoglobina (DOYLE et al., 1967; PENNY et al., 1970). Em amostras de sangue conservadas sob refrigeração por 24 horas, não há alteração nos valores do hematócrito, da hemoglobina e na contagem de células (SCHALM et al., 1986; MORRIS \& DAVEY, 2008). O acondicionamento de um dia para outro, à temperatura ambiente, leva a um pequeno aumento do VCM, o que não é significante, pois permanece similar ao VCM do sangue acondicionado em geladeira (LAWRENCE et al., 1975). Segundo MORRIS \& DAVEY (2008), em amostras com excesso de EDTA, o valor do hematócrito estará falsamente diminuído, devido à contração celular, mas a hemoglobina e as contagens celulares não estarão alteradas. Segundo WEISER (2007), no sangue mantido em temperatura ambiente, o aumento do volume dos eritrócitos entre 6 e 24 horas aumenta o hematócrito e o VCM (MORRIS \& DAVEY, 2008). Em estudo experimental com cães saudáveis e doentes, MEDAILLE et al. (2006), analisando amostras logo após a coleta, com 24 e 48 horas de conservação, observaram que todas as variáveis apresentaram diferença significativa, mas poucos resultados foram considerados inadequados, visto que as alterações foram pouco expressivas. Os referidos autores reforçaram a necessidade de se conhecer as variações provocadas pela ação do tempo sobre as amostras, para que não ocorram equívocos na interpretação dos resultados, principalmente daqueles que se encontram em condições limítrofes.
ROCHA et al. (2001), avaliando sangue humano, concluíram que não foram significativas as diferenças entre os resultados obtidos em diversos tempos de análise $(0,2,4,6,8,10,12$ e 24 horas), após a colheita, nos valores de leucócitos, hemácias, hemoglobina, hematócrito, $\mathrm{VCM}, \mathrm{MCH}, \mathrm{CHCM}, \mathrm{RDW}$, plaquetas, volume plaquetário médio, neutrófilos, linfócitos, eosinófilos e basófilos. Em outro trabalho, LIPPI et al. (2005), analisando amostras de sangue de ciclistas, duas e 24 horas após a coleta, conservadas a $4^{\circ} \mathrm{C}$, detectaram aumentos significativos nos seguintes parâmetros: hematócrito, $\mathrm{VCM}$, porcentagem de macrócitos, plaquetas e volume plaquetário médio (VPM). As variações ocorridas foram modestas e ficaram, quase sempre, dentro dos valores clinicamente aceitáveis. Em estudo realizado com cães da raça beagle, utilizando duas concentrações de EDTA: 1,8mg $\mathrm{mL}^{-1}$ de sangue e $5,4 \mathrm{mg} \mathrm{mL}^{-1}$ de sangue, os resultados mostraram diminuição do hematócrito e do VCM e aumento no CHCM (NEMEC et al., 2005). O presente estudo teve como objetivo identificar os efeitos do tempo, da temperatura de armazenamento e do excesso de anticoagulante sobre parâmetros hematológicos de cães obtidos por automação. É importante lembrar que, independente do tempo de estocagem da amostra, é indispensável que o esfregaço sanguíneo seja confeccionado no momento da coleta, preservando assim a morfologia dos leucócitos.

\section{MATERIAL E MÉTODOS}

Foram utilizados dez cães adultos (seis machos e quatro fêmeas) de peso corporal, idade e raças variadas. Após anti-sepsia, as amostras foram colhidas por venipunção da jugular, onde foi introduzido um cateter, acopladas as seringas e aspirado o sangue, que foi distribuído em 28 tubos plásticos ${ }^{\mathrm{a}}$, totalizando 32 amostras para análise (tempo 0 igual para temperatura ambiente $2^{\circ} \mathrm{C}$ a $8^{\circ} \mathrm{C}$ ), marcados com pincel, indicando o volume correto a ser coletado.

As amostras sanguíneas foram separadas em dois grupos: Grupo 1: amostras em temperatura ambiente e Grupo 2: amostras mantidas entre $2^{\circ} \mathrm{C}$ a $8^{\circ} \mathrm{C}$. Em ambos os grupos, as alíquotas de 0,$25 ; 0,5 ; 1,0$; e $2,0 \mathrm{~mL}$ de sangue foram colhidas em tubos com $3,6 \mathrm{mg}$ de EDTA, proporcionando as seguintes concentrações de EDTA: 14,$4 ; 7,2 ; 3,6$ e 1,8mg mL $\mathrm{mL}^{-1}$ de sangue. As amostras foram avaliadas em quatro tempos: $0,12,24 \mathrm{e}$ 
48 horas após a coleta. Cada tubo foi aberto e manipulado uma única vez, no tempo da respectiva análise. A temperatura do refrigerador foi monitorada com termômetro de máxima e mínima, permanecendo na faixa citada. A temperatura ambiente oscilou entre $22^{\circ} \mathrm{C}$ e $30^{\circ} \mathrm{C}$. As amostras sanguíneas foram analisadas com contador hematológico automático ${ }^{\mathrm{b}}$, para a mensuração dos seguintes parâmetros: leucócitos $\mu \mathrm{L}^{-1}$, hemácias $\mu \mathrm{L}^{-1}$, hemoglobina $\left(\mathrm{g} \mathrm{dL}^{-1}\right)$, hematócrito (\%), volume corpuscular médio (fL), índice de anisocitose eritrocitária (RDW), plaquetas $\mu \mathrm{L}^{-1}$ e plaquetócrito (\%).

Os dados foram arranjados em um esquema fatorial. Para proceder à análise dos dados, foram realizadas a análise de variância (ANOVA) e as médias comparadas pelo teste de Tukey, com 5\% de probabilidade. Foram verificadas as interações entre tempo, temperatura de estocagem e concentração de EDTA. Os dados são apresentados em análise descritiva (médias e desvios-padrão).

\section{RESULTADOS E DISCUSSÃO}

$\mathrm{Na}$ avaliação de eritrócitos e $\mathrm{VCM}$, a temperatura de conservação influenciou o resultado da contagem de eritrócitos com média $6,76 \pm 1,13$ sob refrigeração e 6,44 $\pm 1,14$ em temperatura ambiente. Esse decréscimo provavelmente foi devido à lise das hemácias durante o período de conservação, considerando-se o aumento da temperatura das amostras como provável fator determinante da fragilidade eritrocitária. Entretanto, outros estudos em condições semelhantes (COHLE et al., 1981; HIRASE et al., 1992; FREISE et al., 2008), analisando sangue humano, não evidenciaram diferença significativa no número de eritrócitos em amostras mantidas sob refrigeração e em temperatura ambiente por 48 horas. Como expresso na tabela 1, o VCM apresentou decréscimo nas duas maiores concentrações de EDTA
(7,2 e $14,4 \mathrm{mg} \mathrm{mL}^{-1}$ de sangue). Essa diminuição foi ocasionada pela crenação osmótica das hemácias decorrente do excesso de EDTA. NEMEC et al. (2005) também evidenciaram diminuição do VCM em amostras com alta concentração de EDTA $\left(5,4 \mathrm{mg} \mathrm{mL}^{-1}\right.$ de sangue). No estudo dos referidos autores, os valores do VCM passaram de $74,4 \pm 1,1 \mathrm{fL}$ para $65,4 \pm 3,0 \mathrm{fL}$, diferença de $11,9 \%$, sendo superior aos $2,36 \%$ de redução no presente estudo, quando se utilizou $14,4 \mathrm{mg}$ de EDTA por $\mathrm{mL}$ de sangue. No presente ensaio, o tempo e a temperatura de armazenamento também influenciaram o VCM, ocorrendo interação entre os dois (Tabela 2).

Sob refrigeração, o VCM apresentou diminuição $(\mathrm{P}<0,05)$ no tempo de $12 \mathrm{~h}$. Esta redução pode ser explicada pela crenação osmótica dos eritrócitos. Na temperatura ambiente, o VCM permaneceu sem alterações significativas durante as 12 primeiras horas, mas aumentou significativamente após a $24^{\mathrm{a}}$ hora. Esse acréscimo possivelmente foi determinado pela tumefação celular, que ocorre em amostras mantidas sem refrigeração por longos períodos. Na comparação entre as duas temperaturas, os resultados do VCM permaneceram sem diferença significativa nos tempos $0 \mathrm{~h}$ e $12 \mathrm{~h}$, mas apresentaram diferença $(\mathrm{P}<0,05)$ nos tempos $24 \mathrm{~h}$ e $48 \mathrm{~h}$, com valores maiores na temperatura ambiente. Este aumento no VCM, com o passar do tempo, foi ocasionado também pela tumefação celular, corroborando os dados obtidos, em cães, por MEDAILLE et al. (2006) e em humanos por LAWRENCE etal.(1975), COHLE etal.(1981), LIPPI etal.(2005), WEISER(2007),ALMEIDA(2008) eFREISE et al. (2008). Por sua vez, ROCHA et al. (2001) não detectaram diferença no VCM, durante estudo realizado com sangue humano com vários tempos de avaliações $(0,2,6,8,10,12$ e 24 horas). No entanto, apesar das diferenças, as alterações observadas nos índices do VCM, no presente estudo, mantiveram-se na faixa de referência (SCHALM et al., 1986).

Tabela 1 - Médias e desvios padrão do volume corpuscular médio (VCM) de sangue total canino, conservado em diferentes concentrações de EDTA.

\begin{tabular}{|c|c|c|c|c|}
\hline \multirow{3}{*}{ Parâmetro } & \multicolumn{4}{|c|}{-EDTA (mg mL $\left.{ }^{-1}\right)$} \\
\hline & & & & \\
\hline & 1,8 & 3,6 & 7,2 & 14,4 \\
\hline VCM (fL) & $69,15 \pm 4,22^{\mathrm{A}}$ & $68,24 \pm 3,64^{\mathrm{AB}}$ & $67,60 \pm 3,73^{\mathrm{B}}$ & $67,52 \pm 3,64^{\mathrm{B}}$ \\
\hline
\end{tabular}

Médias e desvios padrão seguidos por letras iguais e na mesma linha não diferem estatisticamente entre si, a $5 \%$ de probabilidade pelo teste de Tukey. 
Tabela 2 - Médias e desvios padrão de volume corpuscular médio (MCV) de sangue total canino, de acordo com a temperatura de conservação e com as medidas nos tempos $0 \mathrm{~h}, 12 \mathrm{~h}, 24 \mathrm{~h}$ e $48 \mathrm{~h}$.

\begin{tabular}{|c|c|c|c|c|c|}
\hline & \multirow{2}{*}{ Temperatura } & \multicolumn{4}{|c|}{--------------------------------------------Tempo em horas------------------------- } \\
\hline & & 0 & 12 & 24 & 48 \\
\hline \multirow[t]{2}{*}{ VCM (fL) } & $2^{\circ} \mathrm{C}$ a $8^{\circ} \mathrm{C}$ & $66,80 \pm 3,04^{\mathrm{ABa}}$ & $66,37 \pm 2,99^{\mathrm{Ba}}$ & $67,57 \pm 3,15^{\mathrm{ABb}}$ & $68,32 \pm 2,99^{\mathrm{ABb}}$ \\
\hline & Ambiente & $66,80 \pm 3,09^{\mathrm{CBa}}$ & $65,92 \pm 3,09^{\mathrm{CBa}}$ & $69,62 \pm 3,00^{\mathrm{Ba}}$ & $73,60 \pm 3,36^{\mathrm{ABa}}$ \\
\hline
\end{tabular}

Nota: Médias e desvios padrão seguidos por letras maiúsculas iguais na mesma linha não diferem entre si ( $\mathrm{P}>0,05)$, pelo teste de Tukey. Médias seguidas por letras minúsculas iguais, na mesma coluna e parâmetro, não diferem entre si $(\mathrm{P}>0,05)$, pelo teste $\mathrm{F}$.

Os valores de hemoglobina, hematócrito, índice de anisocitose eritrocitária (RDW), plaquetas e plaquetócrito não apresentaram alterações entre grupos e nos grupos ao longo do tempo (Tabela 3), corroborando os dados obtidos por HIRASE et al. (1992), FREISE et al. (2008) e IMERI et al. (2008). Por sua vez, COHLE et al. (1981) também detectaram estabilidade da hemoglobina, durante 48 horas, em amostras de sangue humano, conservadas sob refrigeração e em temperatura ambiente. Entretanto registraram aumento no hematócrito, a partir da $48^{\mathrm{a}}$ hora, em amostras conservadas em temperatura ambiente. Ausência de alteração na concentração de hemoglobina com alta concentração de $\operatorname{EDTA}\left(5,4 \mathrm{mg} \mathrm{mL}^{-1}\right)$ também foi constatada por NEMEC et al. (2005). Porém, os referidos autores registraram decréscimo no hematócrito, com aumento da concentração de EDTA, o que não foi observado no presente estudo.

A concentração de EDTA e o tempo de armazenagem não influenciaram os resultados da contagem de leucócitos, nem houve interação entre eles ou deles com a temperatura de conservação. Observou-se que a contagem de leucócitos foi influenciada pela temperatura de conservação

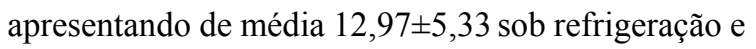
$11,90 \pm 3,59$ em temperatura ambiente. A média menor nas amostras conservadas sob temperatura ambiente provavelmente se deveu ao fato de que, em temperaturas mais elevadas, a lise de leucócitos é maior. Estudando a influência do tempo e da temperatura de armazenagem na conservação sanguínea em três equipamentos distintos, IMERI et al. (2008) detectaram diminuição no número de leucócitos na temperatura ambiente, no tempo 48 horas, em um dos três equipamentos utilizados, enquanto nos resultados obtidos nos outros dois equipamentos, não foi observada diferença. COHLE et al. (1981); HIRASE et al. (1992) e FREISE et al. (2008) não observaram alteração nos valores dos leucócitos em amostras de sangue humano, armazenadas sob refrigeração ou temperatura ambiente, por 48 horas. O número de plaquetas e o plaquetócrito (PCT) também não apresentaram alteração nos estudos feitos por HIRASE et al. (1992) e FREISE et al. (2008). Já IMERI et al. (2008), observando o número de plaquetas de sangue humano, conservado em temperatura ambiente e sob refrigeração em diferentes equipamentos, observaram variações desta estabilidade entre os equipamentos. Esses resultados demonstraram que amostras conservadas sob as mesmas condições de tempo e temperatura podem apresentar alterações importantes, dependendo do aparelho utilizado.

\section{CONCLUSÃO}

O aumento da concentração de EDTA diminui os valores do VCM. Por sua vez, a temperatura de conservação também ocasiona alteração nos valores do VCM, ou seja, há aumento nos seus índices na $24^{\mathrm{a}}$ e $48^{\mathrm{a} h}$ na temperatura ambiente e diminuição na $12^{\mathrm{a}} \mathrm{h}$ na temperatura de 2 a $8^{\circ} \mathrm{C}$. A temperatura ambiente diminui o número de leucócitos e eritrócitos durante a conservação. As alterações observadas não comprometeram os resultados obtidos no contador automático de células, mostrando que as amostras sanguíneas, conservadas por 48 horas, mantiveram-se em boas condições para análise, principalmente quando armazenadas à temperatura de $2 \mathrm{a} 8^{\circ} \mathrm{C}$.

\section{FONTES DE AQUISIÇÃO}

a - Vacuette do Brasil LTDA, Campinas.

b - Humancountplus, Human do Brasil, Itabira-MG 
Tabela 3 - Médias* e desvios padrão de hemoglobina, hematócrito, RDW, plaquetas e plaquetócrito de amostras coletadas em diferentes concentrações de EDTA, armazenadas em duas temperaturas e analisadas em quatro intervalos de tempo.

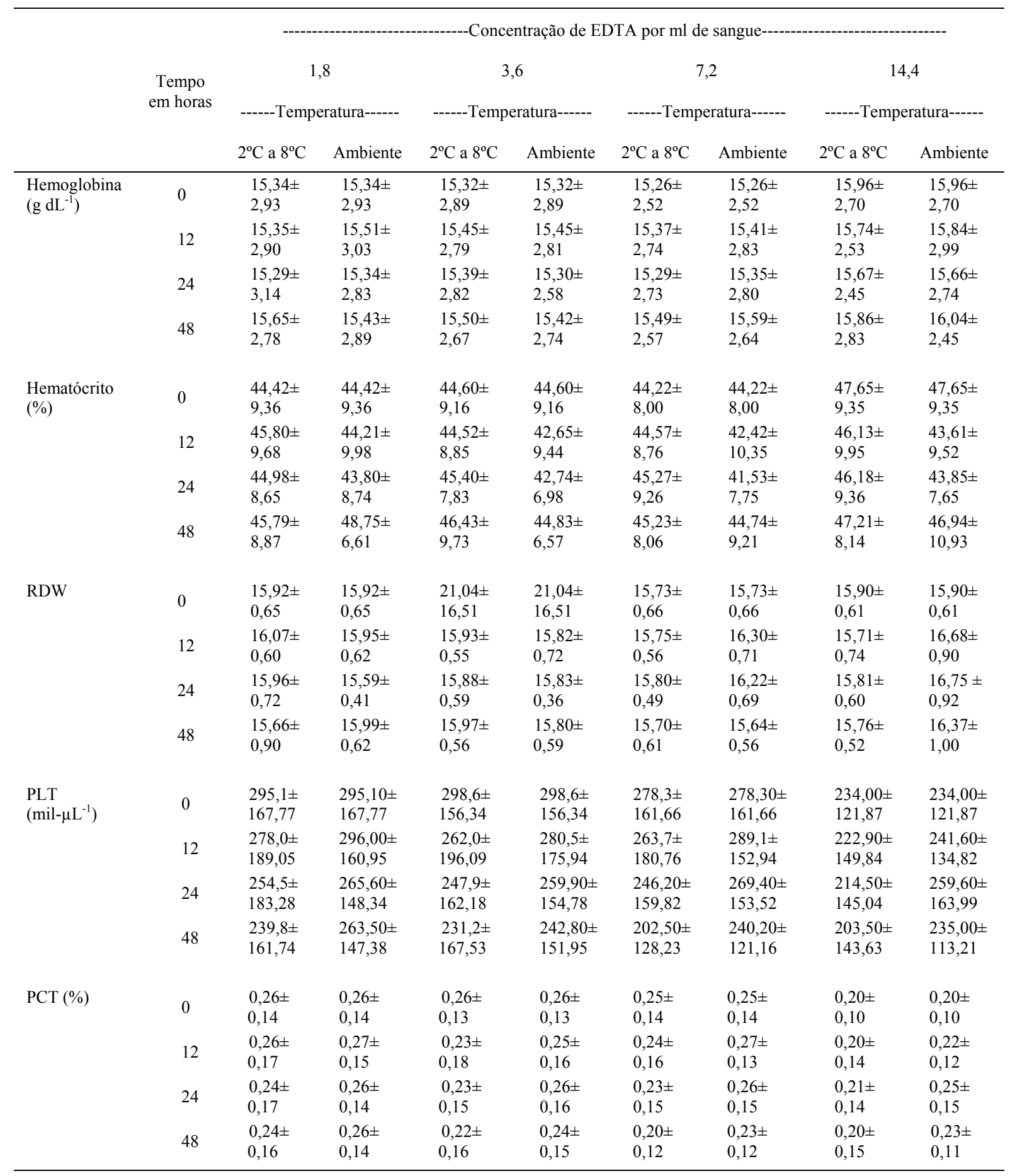

$* \mathrm{P}>0,05$. 


\section{COMISSÃO DE ÉTICA DA UNIVERSIDADE FEDERAL DE VIÇOSA}

Trabalho aprovado pela comissão de ética da Universidade Federal de Viçosa (UFV) sob o número 505542577.

\section{REFERÊNCIAS}

ALMEIDA, T.V. Hematologia; colheita de material. In: MOURA, R.A. Técnicas de laboratório. 3.ed. São Paulo: Atheneu, 2008. p.335-342.

COHLE, E.D. et al. Effects of storage of blood on stability of hematologic parameters. American Society of Clinical Pathologists, v.76, n.1, p.67-70, 1981.

DOYLE, C.T. et al. The effect of blood volume and choice of anticoagulant on the PCV, MCHC and total white cell count. Irish Journal of Medical Science, v.42, n.9, p.429-435, 1967. Disponível em: <http://www.springerlink.com/content/ c3m1230168v19127/>. Acesso: 27 jun. 2009. doi: 10.1007/ BF02954088.

FREISE, K.J. et al. The effect of anticoagulant, storage temperature and dilution on cord blood hematology parameters over time. International Journal of Laboratory Hematology, v.31, n.5, p.496-504, 2008. Disponível em: $<$ http://onlinelibrary.wiley.com/doi/10.1111/clh.2009.31.issue5/issuetoc $>$. Acesso em: 28 jun. 2009. doi: 10.1111/j.1751553X.2008.01066.X

HIRASE, Y. Stable blood cell after one-week storage at room temperature. Bulletin of Environmental Contamination and Toxicology, v.49, n.4, p.504-508, 1992. Disponível em: $<$ http://www.springerlink.com/content/g80x7234308q782g/>. Acesso em: 30 jul. 2009. doi: 10.1007/BF00196290.

IMERI, F. et al. Stability of hematological analytes depends on the hematology analyzer used: a stability study with Bayer Advia 120, Beckman Coulter LH 750 and Sysmex XE 2100. Clinica Chimica Acta, v.397, n.1-2 p.68-71, 2008. Disponível em: $<$ http://www.ncbi.nlm.nih.gov/pubmed/18706900>. Acesso em: 15 jun. 2009. doi: 10.1016/j.cca.2008.07.018.

LAWRENCE. A.C.K. et al. Storage of blood and mean corpuscular volume. Journal of Clinical Pathology, v.28, n.5 p.345-
349, 1975. Disponível em: <http://jcp.bmj.com/content/vol28/ issue 5/>. Acesso em: 26 jun. 2009. doi: 10.1136/jep.28.5.345.

LIPPI, G. et al. Stability of blood cell counts, hematologic parameters and reticulocytes indexes on the Advia A 120 hematologic analyzer. Journal of Laboratory and Clinical Medicine, v.146, n.6, p.333-340, 2005.

MEDAILLE, C. et al. Stability of selected hematology variables in canine blood kept at room temperature in EDTA for 24 and 48 hours. Veterinary Clinical Pathology, v.35, n.1, p.18$23,2006$.

MORRIS, M.W.; DAVEY, F.R. Exame básico do sangue. In: HENRY, J.B. Diagnósticos clínicos e tratamento por métodos laboratoriais. 20.ed. Barueri: Manole, 2008. Cap.24, p.559604.

NEMEC, A. et al. The effect of high anticoagulant k3-edta concentration on complete blood count and white blood cell differential counts in healthy beagle dogs. Slovenian Veterinary Research, v.42, n.3/4, p.65-70, 2005.

PENNY, R.H.C. et al. Some observations on the effect of the concentration of ethulenediamine tetra acetic acid (EDTA) on the pached cell volume of domesticated animals. British Veterinary Journal, v.126, n.7, p.383-389, 1970.

ROCHA, H.H.G. et al. Estudo da interferência do anticoagulante nos índices do hemograma, relacionados ao tempo pós coleta. Rio de Janeiro: Setor de hematologia do Laboratório Diagnóstico das Américas, 2001. Acessado em: 22 mar. 2009. Online. Disponível em: <http://www.heloisa.med.br/ EDTAEleuza.htm>.

SCHALM, O.W. et al. Hematologic techniques. In: FELDMAN et al. Schalm's veterinary hematology. 4.ed. Philadelphia: Lea \& Febiger, 1986. Cap.2, p.20-86.

SCHALM, O.W. et al. The dog: normal hematology with comments on response to disease. In: FELDMAN et al. Schalm's veterinary hematology. 4.ed. Philadelphia: Lea \& Febiger, 1986. Cap.4, p.103-125.

WEISER, G. Coleta e processamento de amostras e análise das opções de serviços laboratoriais. In: THRALL, M.A. et al. Hematologia e bioquímica clínica veterinária. São Paulo: Roca, 2007. Cap.2, p.37-42. 